\title{
Are doctors assessing patients with hypertension appropriately at their initial presentation?
}

\author{
Siew Lee Stalia Wong${ }^{1}$, MMed, Ping Yein $\underline{L e}^{2}$, MMed, Chirk Jenn $\underline{N g}^{3}$, PhD, Nik Sherina $\underline{H a n a f i}^{3}$, PhD, \\ Yook Chin $\underline{C h i a}^{3}$, MBBS, FRCP, Pauline Siew Mei Lai ${ }^{3}$, PhD, Su May Liew ${ }^{3}$, DPhil, Ee Ming Khoo ${ }^{3}$, MD
}

INTRODUCTION The aim of this study was to determine the extent to which primary care doctors assessed patients newly diagnosed with hypertension for the risk factors of cardiovascular disease (CVD) during the patients' first clinic visit for hypertension. The study also aimed to examine the trend of assessment for CVD risk factors over a 15-year period. METHODS This retrospective study was conducted between January and May 2012. Data was extracted from the paperbased medical records of patients with hypertension using a 1:4 systematic random sampling method. Data collected included CVD risk factors and a history of target organ damage (TOD), which were identified during the patient's first visit to the primary care doctor for hypertension, as well as the results of the physical examinations and investigations performed during the same visit.

RESULTS A total of 1,060 medical records were reviewed. We found that assessment of CVD risk factors during the first clinic visit for hypertension was poor (5.4\%-40.8\%). Assessments for a history of TOD were found in only $5.8 \%-11.8 \%$ of the records, and documented physical examinations and investigations for the assessment of TOD and secondary hypertension ranged from $0.1 \%-63.3 \%$. Over time, there was a decreasing trend in the percentage of documented physical examinations performed, but an increasing trend in the percentage of investigations ordered.

CONCLUSION There was poor assessment of the patients' CVD risk factors, secondary causes of hypertension and TOD at their first clinic visit for hypertension. The trends observed in the assessment suggest an over-reliance on investigations over clinical examinations.

Keywords: cardiovascular disease, end-organ damage, first visit, hypertension, risk factor

\section{INTRODUCTION}

Hypertension is a major public health concern. According to the World Health Organization, hypertension accounts for $4.5 \%$ of the global disease burden. ${ }^{(1)}$ It has been predicted that by 2025 , there will be a $60 \%$ increase in the number of hypertensive adult patients globally (from 972 million in 2000 to 1.56 billion). ${ }^{(2)}$ Worldwide, the prevalence of hypertension varies from $5.2 \%$ to $70.7 \% .^{(3)}$ In Malaysia, it is estimated that $43 \%$ of adults over the age of 30 have hypertension. ${ }^{(4)}$

Hypertension is associated with an increased risk of cardiovascular, cerebrovascular and renal diseases. This in turn leads to increased healthcare costs, which imposes substantial demands on national budgets. Many international and local clinical practice guidelines (CPGs) for hypertension have been published to help improve the quality of care for patients with hypertension and minimise healthcare burdens. ${ }^{(5-8)}$ The Malaysian CPG for hypertension, first published in 1998, was revised in 2002 and 2008. ${ }^{(5-7)}$ Most guidelines emphasise the importance of a thorough assessment for cardiovascular disease (CVD) risk factors, target organ damage (TOD) and secondary causes of hypertension when patients first present with hypertension..$^{(5-7,9)}$ Despite these efforts, one study has shown that up to $53 \%$ of patients with hypertension did not receive adequate CVD risk assessment. ${ }^{(10)}$

CVD risk factors, apart from hypertension, include advanced age (male $\geq 45$ years, female $\geq 55$ years), male gender, current cigarette smoking, a family history of myocardial infarction or sudden death (before the age of 55 years in a male parent or male first degree relative, and before 65 years in a female parent or female first degree relative), dyslipidaemia and diabetes mellitus. ${ }^{(11,12)}$ Modifiable CVD risk factors should be actively managed in patients with hypertension to reduce their global cardiovascular risk.

Although hypertension is a very common condition in the primary care setting, little is known about the initial evaluation of hypertension performed in this setting. Therefore, the present study aimed to determine the extent to which primary care doctors assessed CVD risk factors in patients newly diagnosed with hypertension during their first clinic visit. The study also aimed to examine the trend of assessment for CVD risk factors over a 15-year period, from 1998 to 2012. This time period was chosen to coincide with the publication of the first edition of the Malaysian CPG for hypertension in 1998 and the second edition in 2002, and covers the four years after the publication of the third edition in 2008, so that we could examine if there was any correlation between our data and changes in the criteria of the Malaysian CPG for hypertension.

\section{METHODS}

This study was conducted at the University of Malaya Primary Care Clinic, an academic primary care practice in Malaysia. 
About 400-600 patients are seen daily at this clinic by a pool of 25-30 doctors, comprising family medicine trainees and trained family physicians. About a quarter of the patients had hypertension.

Our study was part of a larger study assessing adherence to CPGs for hypertension. Baseline data from the larger study was used in the present study. The medical records of all patients with hypertension who attended the clinic within a five-month period, between January and May 2012, were reviewed. Patients who were aged above 18 years and had been followed up at the clinic for hypertension for at least one year were included in the study. The paper-based records of these patients were then selected using a 1:4 systematic random sampling method. The records were reviewed and data on the patients' first visit for hypertension was extracted. For the purpose of this study, a patient was taken to have hypertension if he had a diagnosis of hypertension in his medical records and/or was on antihypertensive medication.

An electronic, self-designed data collection form was used to record the patients' sociodemographic characteristics and clinical data (e.g. CVD risk factors, TOD, secondary causes and investigation results) during their first clinic visit. If the presence or absence of a condition was documented in the medical records, it was noted as a 'yes' or 'no', respectively. If the condition was not mentioned in the records, it was noted as 'not done', even though the patient may have been evaluated for the condition with no documentation of the results.

Data collected included documentation of previous myocardial infarction, ischaemic heart disease, left ventricular hypertrophy, heart failure, stroke/transient ischaemic attack, peripheral vascular disease, renal impairment, diabetes mellitus, dyslipidaemia, smoking status, and family history of early cardiovascular death, ischaemic heart disease, hypertension, diabetes mellitus, renal impairment, stroke and dyslipidaemia. We also collected data from the patients' physical examinations. This included information such as weight, height, peripheral pulses, carotid bruit, and the results of cardiovascular, respiratory, abdominal, and neurological and fundus examinations. The results of examinations for signs of endocrine disorders, such as Cushing syndrome, thyroid disorders and acromegaly, were also collected. In terms of investigations performed, results of the renal profile, uric acid, lipid profile, full blood count, fasting blood glucose, electrocardiography, chest radiograph, urine and microalbuminuria assessments were collected. Data collection was done by two trained research assistants.

Data analysis was performed using PASW Statistics version 18.0 (SPSS Inc, Chicago, IL, USA). Accuracy of the data was ensured via double data entry and a random audit of data by the researchers. Demographic data and rates of all the assessments at the first clinic visit were summarised using descriptive frequencies. Pearson's chi-square test was used to examine the associations between categorical variables. In order to subanalyse patients with different CVD risks according to their gender and age (as recommended by the guidelines), the patients were categorised into: (a) a younger group, which included males aged $<45$ years and females aged $<55$ years (i.e. low risk); and (b) an older group, which included males aged $\geq 45$ years and females aged $\geq 55$ years (i.e. high risk). ${ }^{(11,12)}$ Documentation of assessments performed for CVD risk factors (i.e. physical examinations and investigations) were also analysed over a time period that corresponded to the publication of the Malaysian CPGs for hypertension. ${ }^{(5-7)}$ The documents were divided into three groups according to the dates of the patients' first clinic visit for hypertension: Group 1 (February 1998-January 2002), Group 2 (February 2002-January 2008) and Group 3 (February 2008-May 2012). Frequencies of CVD risk factors were used to compare between the groups.

Ethics approval was obtained from the University of Malaya Medical Ethics Committee (Reference: 890.14). Data collected was anonymised to ensure patient confidentiality.

\section{RESULTS}

About 4,000 patients with hypertension attended the clinic during the study period and we reviewed the medical records of 1,060 patients. The mean age of the patients was $62.6 \pm 10.5$ years and the mean duration of hypertension was $8.5 \pm 6.4$ years. Only $5.5 \%$ of the patients were aged $<40$ years at the time of their first visit to the clinic for hypertension. More than half of the patients were female (59.7\%). The ethnic distribution was $48.0 \%$ Chinese, $30.5 \%$ Malay, $20.6 \%$ Indian and $0.9 \%$ other ethnicities.

Table I shows the rate of assessment of history for CVD risk factors and TOD during the patients' first visit to the clinic for hypertension. Overall, the level of assessment for CVD risk factors was poor. The absence or presence of diabetes mellitus, smoking and dyslipidaemia was documented in $\leq 40 \%$ of the patient records. Only $5.4 \%$ of the records contained documentation of a family history of premature CVD. Assessments of a history of TOD during the first clinic visit were found in only about $10 \%$ or less of the records.

Table II summarises the rates of assessment of physical examinations and investigations performed during the first visit for hypertension. Physical assessments for TOD and secondary hypertension (e.g. examinations of the fundus, neurological system, carotid and peripheral pulses and thyroid, and examinations for Cushing syndrome and acromegaly) were documented in about $10 \%$ or less of the records, while cardiovascular and respiratory examinations were documented in about $60 \%$ of the records. The patient's weight was assessed in less than half of the records. Some investigations, namely electrocardiogram, urine analysis, chest radiograph, full blood count and uric acid test, were documented in $\leq 20 \%$ of the records. About half of the records had documented assessments of renal function, lipid profile and fasting blood glucose.

When the records of the older patients (i.e. male patients aged $\geq 45$ years or female patients aged $\geq 55$ years) were compared with those of the younger patients (male patients aged $<45$ years or female patients aged $<55$ years), Pearson's chi-square test showed that the rates of assessment for a family history of hypertension, fundus examination and urinalysis were significantly higher among the younger patients. Older patients had significantly higher rates of assessment for smoking and dyslipidaemia as compared to the younger patients. 
Table I. Rates of documentation of history of cardiovascular disease (CVD) risk factors and target organ damage.

\begin{tabular}{|c|c|c|c|c|}
\hline \multirow[t]{2}{*}{ Variable } & \multicolumn{3}{|c|}{$\%$} & \multirow[t]{2}{*}{ p-value } \\
\hline & $\begin{array}{l}\text { All patients with } \\
\text { hypertension } \\
(n=1,060)\end{array}$ & $\begin{array}{c}\text { Male patients } \\
\text { aged }<45 \text { years or female } \\
\text { patients aged }<55 \text { years } \\
\text { with hypertension }(n=324)\end{array}$ & $\begin{array}{c}\text { Male patients } \\
\text { aged } \geq 45 \text { years or female } \\
\text { patients aged } \geq 55 \text { years } \\
\text { with hypertension }(n=736 \text { ) }\end{array}$ & \\
\hline \multicolumn{5}{|l|}{ Personal history } \\
\hline Diabetes mellitus & 40.8 & 42.0 & 40.4 & 0.621 \\
\hline Smoking status & 29.7 & 25.0 & 31.8 & $0.026^{*}$ \\
\hline Dyslipidaemia & 28.0 & 23.1 & 30.2 & $0.019 *$ \\
\hline Ischaemic heart disease & 11.8 & 12.0 & 11.7 & 0.870 \\
\hline Stroke/transient ischaemic attack & 11.6 & 9.9 & 12.4 & 0.244 \\
\hline Angina & 8.3 & 9.6 & 7.7 & 0.322 \\
\hline Renal problems & 6.5 & 8.0 & 5.8 & 0.185 \\
\hline Myocardial infarction & 5.9 & 7.1 & 5.4 & 0.291 \\
\hline Peripheral vascular disease & 5.8 & 7.1 & 5.3 & 0.250 \\
\hline \multicolumn{5}{|l|}{ Family history } \\
\hline Hypertension & 24.7 & 31.8 & 21.6 & $0.001^{*}$ \\
\hline Diabetes mellitus & 20.8 & 23.8 & 19.6 & 0.121 \\
\hline Ischaemic heart disease & 14.9 & 15.4 & 14.7 & 0.749 \\
\hline Stroke & 9.5 & 9.3 & 9.6 & 0.843 \\
\hline Dyslipidaemia & 5.8 & 5.9 & 5.8 & 0.989 \\
\hline Renal problem & 5.5 & 4.0 & 6.1 & 0.166 \\
\hline Early CVD & 5.4 & 3.7 & 6.1 & 0.109 \\
\hline
\end{tabular}

* Statistical significance set at $\mathrm{p}<0.05$.

Table II. Rates of documentation of physical examinations and investigations.

\begin{tabular}{|c|c|c|c|c|}
\hline \multirow[t]{2}{*}{ Variable } & \multicolumn{3}{|c|}{$\%$} & \multirow[t]{2}{*}{ p-value } \\
\hline & $\begin{array}{l}\text { All patients with } \\
\text { hypertension } \\
\text { (n=1,060) }\end{array}$ & $\begin{array}{c}\text { Male patients } \\
\text { aged }<45 \text { years or female } \\
\text { patients aged }<55 \text { years } \\
\text { with hypertension }(n=324)\end{array}$ & $\begin{array}{c}\text { Male patients } \\
\text { aged } \geq 45 \text { years or female } \\
\text { patients aged } \geq 55 \text { years } \\
\text { with hypertension }(n=736)\end{array}$ & \\
\hline \multicolumn{5}{|l|}{ Physical examination } \\
\hline Lung examination & 63.6 & 64.2 & 63.3 & 0.688 \\
\hline Cardiac examination & 61.4 & 61.7 & 61.3 & 0.889 \\
\hline Weight & 45.6 & 47.2 & 44.8 & 0.473 \\
\hline Abdominal examination & 38.9 & 42.3 & 37.4 & 0.130 \\
\hline Fundus/eye examination & 11.1 & 14.8 & 9.5 & $0.010^{*}$ \\
\hline Neurological examination & 10.2 & 10.5 & 10.1 & 0.828 \\
\hline Peripheral pulses & 8.0 & 7.1 & 8.4 & 0.464 \\
\hline Thyroid examination & 0.9 & 1.5 & 0.7 & 0.180 \\
\hline Acromegaly & 0.3 & 0.6 & 0.1 & 0.174 \\
\hline Cushing syndrome & 0.1 & 0.3 & 0.0 & 0.132 \\
\hline \multicolumn{5}{|l|}{ Investigation } \\
\hline Renal function test & 47.3 & 47.2 & 47.3 & 0.986 \\
\hline Lipid profile & 46.3 & 46.0 & 46.5 & 0.885 \\
\hline Fasting blood sugar & 45.2 & 46.6 & 44.6 & 0.512 \\
\hline Electrocardiography & 20.4 & 20.1 & 20.5 & 0.866 \\
\hline UFEME & 20.2 & 24.4 & 18.3 & $0.024^{*}$ \\
\hline Chest radiography & 8.1 & 8.6 & 7.9 & 0.676 \\
\hline Full blood count & 7.1 & 8.0 & 6.7 & 0.424 \\
\hline Uric acid & 3.3 & 3.4 & 3.3 & 0.910 \\
\hline
\end{tabular}

* Statistical significance set at $p<0.05$. UFEME: urine full examination, microscopic examination 


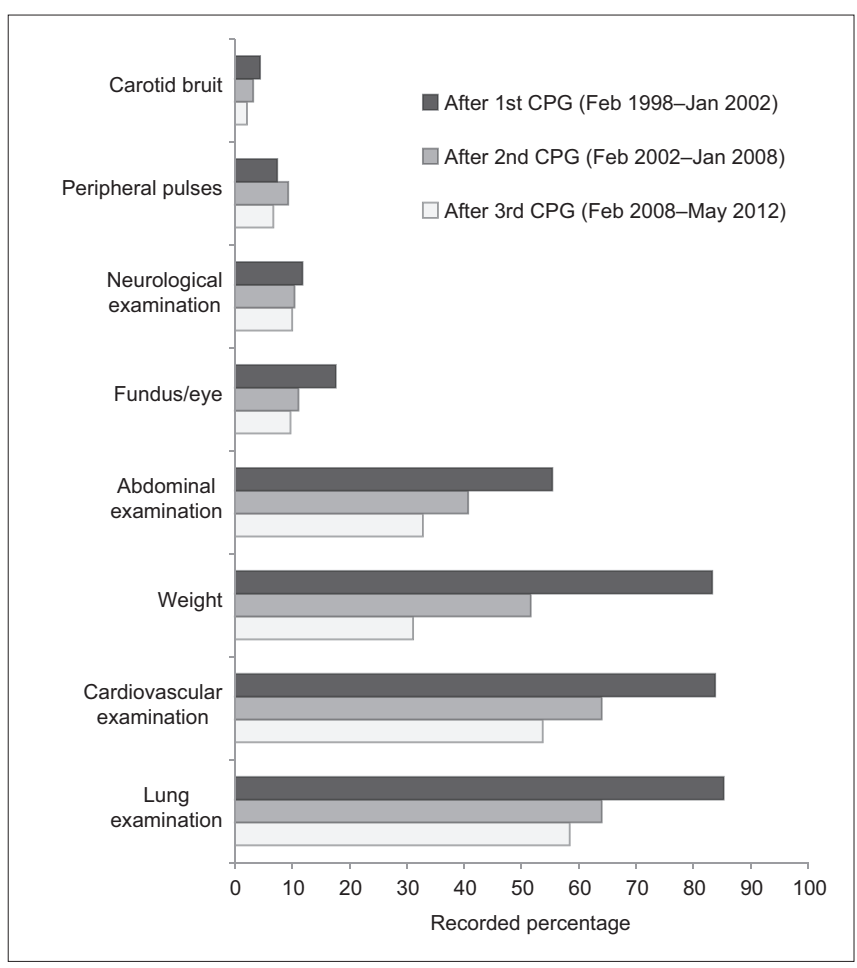

Fig. 1 Bar graph shows the trend in the assessment of cardiovascular disease risk factors via physical examinations from 1998-2012, with the data categorised into time periods according to the publication/revision of the Malaysian clinical practice guidelines (CPGs) for hypertension.

Figs. 1 \& 2 show the trend of assessment for CVD risk factors from 1998 to 2012 . The time periods were divided according to the publication/revision of the Malaysian CPGs for hypertension. Fig. 1 shows a decrease in the percentage of physical examinations documented over time and Fig. 2 shows an increase in the percentage of investigations documented over the same period of time.

\section{DISCUSSION}

The results of the present study showed that there was poor assessment of patients' CVD risk factors, secondary causes of hypertension and TOD during their first clinic visit for hypertension. This is similar to the findings of a study conducted in the United Kingdom ${ }^{(13)}$ that suggested the presence of a gap in the clinical care for hypertension; in particular, missed opportunities to detect and prevent CVD and TOD. This gap could have a negative impact on the morbidity and mortality of such patients. Risk stratification for CVD is one of the most important components in the evaluation of patients with hypertension, as it helps to prevent future complications and determine the aggressiveness of the treatment required. ${ }^{(7,8)}$

The patient load in primary care is often heavy, resulting in short consultation times. In the present study's setting, the patient load was worsened by the lack of an appointment system (i.e. patients were allowed to make unscheduled visits). It was also possible that the doctors assessed the patients without documenting the clinical data in their medical records. Adoption of an electronic health records system could be used as a means to improve documentation under such circumstances. ${ }^{(14)}$

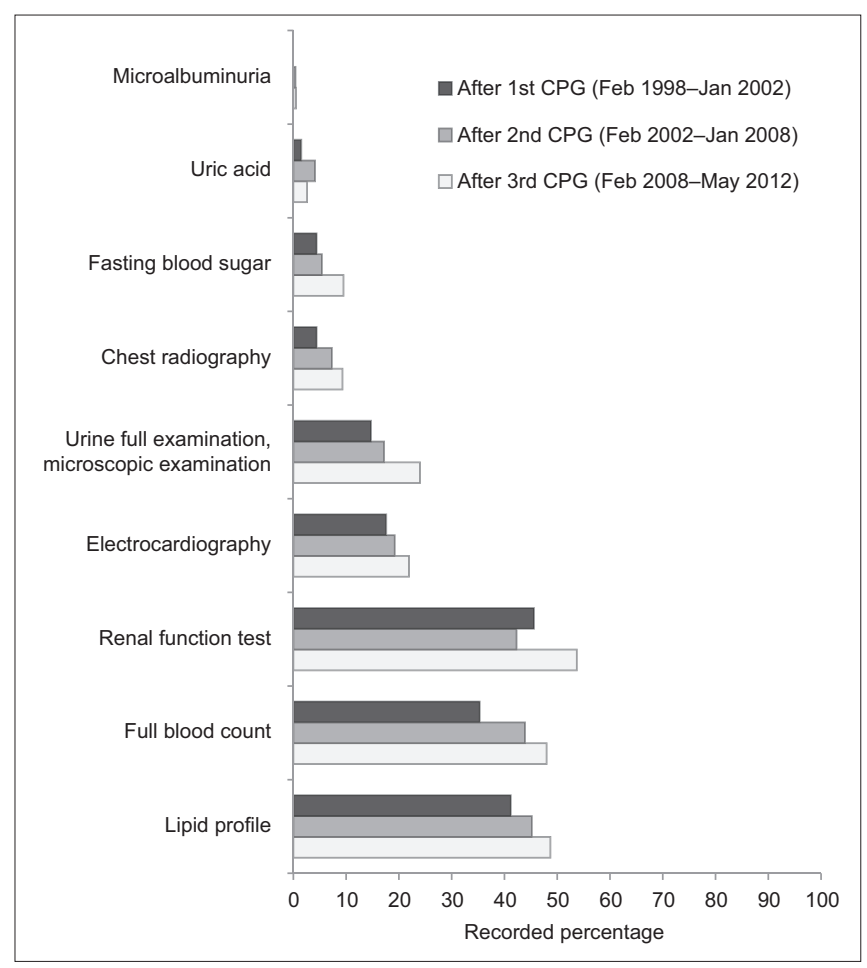

Fig. 2 Bar graph shows the trend in the assessment of cardiovascular disease risk factors via investigations from 1998-2012, with the data categorised into time periods according to the publication/revision of the Malaysian clinical practice guidelines (CPGs) for hypertension.

However, even in one study that used an electronic database, lipid investigations were only documented in a third of the patients. ${ }^{(15)}$ Other studies have advocated the use of incentive systems, albeit with modest improvements in the quality of care. ${ }^{(16)}$ There are other strategies to facilitate the adoption of CPGs, such as practice facilitation, interactive education and reminder systems. ${ }^{(17-21)}$ Further research needs to be conducted to determine which strategy would be most effective in improving the process of care for hypertensive patients in the primary care setting.

Interestingly, in the present study, a greater proportion of the younger patients (i.e. males aged $<45$ years and females aged $<55$ years) had documented assessments of a family history of hypertension, fundus examination and urinalysis compared to the older patients (i.e. males aged $\geq 45$ years or females aged $\geq 55$ years). It is possible that the doctors were stratifying the possibility of secondary causes of hypertension (e.g. renal disease) and associating the patient's family history of hypertension with essential hypertension in the younger patients. Up to $15 \%$ of all hypertension cases could be due to secondary causes. ${ }^{(22,23)}$ Although the rate of secondary hypertension in younger patients is not known, it is still important to look for these secondary causes as they are potentially curable.

We found a decreasing trend in the percentage of documented physical examinations conducted and an increasing trend in the percentage of documented investigations conducted for the evaluation of hypertension during a patient's first clinic visit. This suggests a decline in the use of clinical skills and an increased use of investigations in the assessment of CVD risk factors and TOD. In clinical practice, most diagnoses are attained through clinical 
assessment. ${ }^{(24,25)}$ Only $4.8 \%-7.5 \%$ of diagnoses are attained through further laboratory testing. ${ }^{(24,26)}$ Clinical skills, which include history-taking and physical examination, were once the primary means by which diagnosis and clinical monitoring were done. However, the findings of the present study indicate that these clinicians placed little importance on physical examinations and relied more on investigations for their assessment, as was observed elsewhere. ${ }^{(27)}$

The present study was limited by its retrospective design. Some doctors might not have documented negative findings in their records, leading to an underestimated rate of assessment. In addition, since the study was carried out in a single centre, the findings may not be representative of all medical facilities in Malaysia. Nevertheless, as the sample used was large and selected using systematic random sampling, our findings offer insights into the process of care of hypertensive patients in a primary care setting.

In the present study, we captured the baseline practice of doctors in a real-life setting and examined the impact of Malaysian CPGs on clinical practice over a 15-year period without intervention. In conclusion, there was poor assessment of CVD risk factors, secondary causes and TOD during the patients' first clinic visit for hypertension. This could result in missed opportunities for early intervention to prevent morbidity and mortality due to CVD. The trends in assessment suggest an over-reliance on investigations over physical examination. Further research is required to explore the reasons for the levels of poor assessment and the decreasing practice of clinical examinations in primary care. Our findings will be used to develop an intervention that includes improved clinical workflow, use of record templates and training of healthcare providers to improve practice.

\section{ACKNOWLEDGEMENTS}

The authors would like to express their gratitude to the doctors and staff of the Primary Care Clinic, University of Malaya, Kuala Lumpur, Malaysia. This study was funded by the Institute of Research Management \& Monitoring University Malaya Research Grant RG335/11HTM.

\section{REFERENCES}

1. Whitworth JA; World Health Organization, International Society of Hypertension Writing Group. 2003 World Health Organization (WHO)/ International Society of Hypertension (ISH) statement on management of hypertension. J Hypertens 2003; 21:1983-92.

2. Kearney PM, Whelton M, Reynolds K, et al. Global burden of hypertension: analysis of worldwide data. Lancet 2005; 365:217-23.

3. Kearney PM, Whelton M, Reynolds K, Whelton PK, He J. Worldwide prevalence of hypertension: a systematic review. J Hypertens 2004; 22:11-9.

4. Institute of Public Health. The Third National Health and Morbidity Survey 2006 Vol 2. Kuala Lumpur: Ministry of Health Malaysia, 2006; 199-316.

5. Hypertension Consensus Committee. Approach to the management of hypertension. Available at: http://www.acadmed.org.my/view_file. cfm?fileid=226. Accessed July 272015.
6. Malaysian Society of Hypertension. Clinical Practice Guidelines: Management of Hypertension. 2nd ed. Putrajaya: Ministry of Health Malaysia, 2002:1-56.

7. Ministry of Health Malaysia. Clinical Practice Guidelines: Management of Hypertension. 3rd ed. Available at: http://www2.moh.gov.my/ attachments/3885. Accessed July 27, 2015.

8. National Institute for Health and Care Excellence/BHS. NICE clinical guideline 34. In: Management of hypertension in adults in primary care [online] 2006. Available at: https://www.nice.org.uk/guidance/cg34. Accessed July 27, 2015.

9. National Institute for Health and Care Excellence. NICE clinical guideline 127. In: Hypertension: Clinical management of primary hypertension in adults [online] 2011. Available at: https://www.nice.org.uk/guidance/ cg127. Accessed July 27, 2015.

10. Roslan Johari MG, Pillay MS, Saiful Safuan MS, et al. The adequacy of outpatient management of essential hypertension at ministry of health hospitals and clinics. J Health Manag 2007; 3:67-80.

11. Ministry of Health Malaysia. Clinical Practice Guidelines: Management of Dyslipidemia 2011. 4th ed. Putrajaya: Ministry of Health Malaysia, 2011:3.

12. National Cholesterol Education Program (NCEP) Expert Panel on Detection, Evaluation, and Treatment of High Blood Cholesterol in Adults (Adult Treatment Panel III). Third Report of the National Cholesterol Education Program (NCEP) Expert Panel on Detection, Evaluation, and Treatment of High Blood Cholesterol in Adults (Adult Treatment Panel III) final report. Circulation 2002; 106:3143-421.

13. MacDonald TM, Morant SV, Mozaffari E. Treatment patterns of hypertension and dyslipidaemia in hypertensive patients at higher and lower risk of cardiovascular disease in primary care in the United Kingdom. J Hum Hypertens 2007; 21:925-33.

14. Weinfeld JM, Davidson LW, Mohan V. Electronic health records improve the quality of care in underserved populations: a literature review. J Health Care Poor Underserved 2012; 23(3 Suppl):136-53.

15. Hippisley-Cox J, Coupland C, Vinogradova Y, et al. Predicting cardiovascular risk in England and Wales: prospective derivation and validation of QRISK2. BMJ 2008; 336:1475-82.

16. Gillam S, Siriwardena AN, eds. The quality and outcomes framework QOF-transforming general practice. Oxfordshire: Radcliffe Publishing Ltd, 2010.

17. Harvey G, Loftus-Hills A, Rycroft-Malone J, et al. Getting evidence into practice: the role and function of facilitation. J Adv Nurs 2002; 37:577-88.

18. Rhydderch M, Edwards A, Marshall M, Elwyn G, Grol R. Developing a facilitation model to promote organisational development in primary care practices. BMC Fam Pract 2006; 7:38.

19. Taylor EF, Machta RM, Meyers DS, Genevro J, Peikes DN. Enhancing the primary care team to provide redesigned care: the roles of practice facilitators and care managers. Ann Fam Med 2013; 11:80-3.

20. Asmar R, Achouba A, Brunel P, et al. A specific training on hypertension guidelines improves blood pressure control by more than $10 \%$ in hypertensive patients: the VALNORM study. J Am Soc Hypertens 2007; 1:278-85.

21. Baskerville NB, Liddy C, Hogg W. Systematic review and meta-analysis of practice facilitation within primary care settings. Ann Fam Med 2012; 10:63-74.

22. Sukor N. Secondary hypertension: a condition not to be missed. Postgrad Med J 2011; 87:706-13.

23. Viera AJ, Neutze DM. Diagnosis of secondary hypertension: an age-based approach. Am Fam Physician 2010; 82:1471-8.

24. Hampton JR, Harrison MJ, Mitchell JR, Prichard JS, Seymour C. Relative contributions of history-taking, physical examination, and laboratory investigation to diagnosis and management of medical outpatients. $\mathrm{Br}$ Med J 1975; 2:486-9.

25. Sibbald M, Panisko D, Cavalcanti RB. Role of clinical context in residents' physical examination diagnostic accuracy. Med Educ 2011; 45:415-21.

26. Boland BJ, Wollan PC, Silverstein MD. Yield of laboratory tests for casefinding in the ambulatory general medical examination. Am J Med 1996; 101:142-52.

27. Greenberg J, Green JB. Over-testing: why more is not better. Am J Med $2014 ; 127: 362-3$ 